\title{
Ring-tailed Lemur (lemur catta) behaviour and nutrition at Cotswold Wildlife Park
}

E J Farhall, J C Litten-Brown

University of Reading, Reading, United Kingdom

Email: c.rymer@reading.ac.uk

Introduction Walk-through enclosures have initiated the debate as to whether humans are a form of enrichment or stressful excitement with results of behaviour studies arguing each side. Mallapur et al. (2005) noted the long term effect of visitors caused a 30\% increase in abnormal behaviours but Simpson (2004) contradicts this by observing a positive effect of visitors to red-ruffed lemurs in a walk-through enclosure. Captive diets are formulated to provide a balanced diet but when scatter feeding a group it is difficult to determine whether each animal is eating a correct ratio of feed. The objective of this study was to evaluate the welfare of a troop of Ring-Tailed Lemurs (lemur catta) in a walk-through enclosure at Cotswold Wildlife Park (CWP).

Materials and methods Having established an ethogram of behaviours (ranging from foraging and grooming through to aggression or playing), the nine (5 male, 4 female) lemurs were observed for 3 hours a day (0930-1030 no visitors; 1130 1230 visitors present and 1400-1500 visitors present until 1430) using scan sampling. Scan sampling is a method where the behaviour of each animal is observed every minute for the trial period. Hence every minute it was noted down how many lemurs were in an area and what behaviour they were doing. Results were compared throughout the observation period and to previous studies completed on these animals (Kent, 2008; Williams \& Litten-Brown, 2008). The nutritional observations were focussed on four adults and two juveniles ( 3 male, 4 female). The males and females were observed separately for am and pm feeds $(n=11)$. At each feeding time a balanced diet $(43 \%$ apple and pear; $57 \%$ carrot/turnip and parsnip) was fed, observations were made at the feeding time to ascertain if each individual received this balanced diet results were compared to the expected diets. The data was analysed with General Linear Model in Minitab® 15.1.1.0.

Results Lemur behaviour was significantly affected by weather $(\mathrm{P}<0.001)$ but not by time or visitor presence whereas enclosure use was affected by weather, time and visitor presence (data not shown). For example the lemurs spent approximately twice as long resting when it was raining compared to overcast or sunny weather. Interestingly no lemur consumed the correct ratio of fresh food as they were expected to with their diet formulation with males and females showing different food preferences.

Graph 1 A graph to show the total percentage of fresh food consumed per lemur during AM study sessions in comparison with their expected consumption

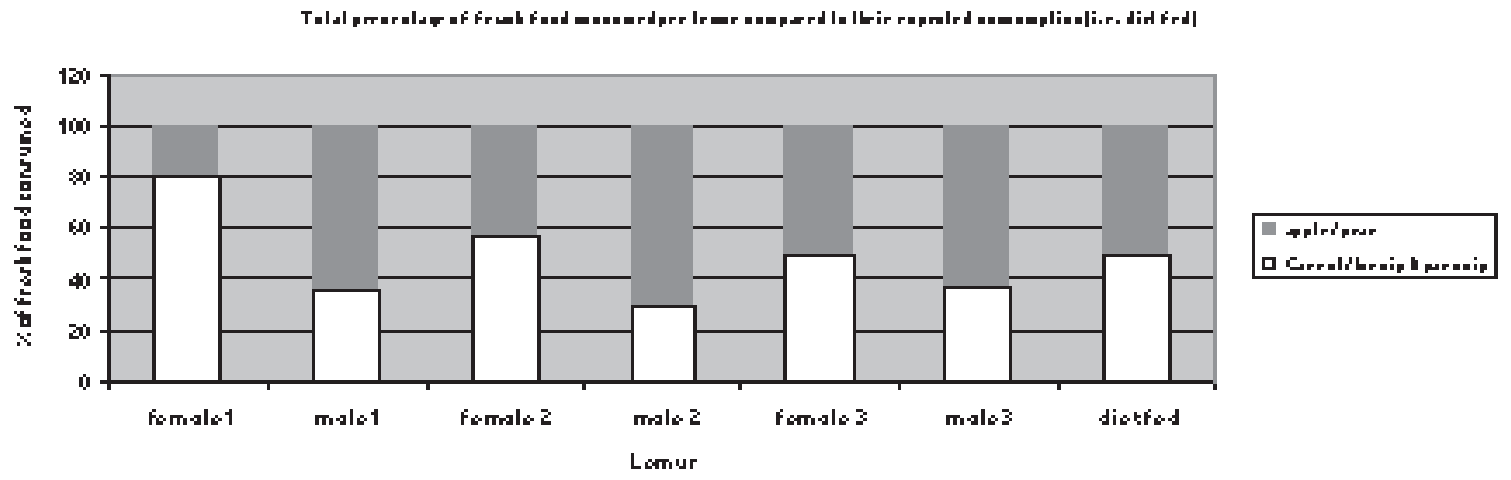

Conclusions Williams and Litten-Brown (2008) concluded the walk-through enclosure at CWP provided positive enrichment, this study several months later would tend to agree due to behaviour being similar to that found in the wild (Sussman, 1977). However the lemurs were exhibiting unnatural behaviour toward visitors such as jumping on prams looking for food. The whole of the enclosure was utilised with the lemurs moving from one end to the other in a particular pattern each day. Lemurs received their am \& pm feeds indoors where it was obvious one female had dominance over what the others ate, as is the norm in lemur social hierarchy (Sussman, 1977). The findings have implications in attempting to ensure that all animals receive a balanced diet.

Acknowledgements The authors would like to thank Cotswold Wildlife Park for their assistance in this study.

\section{References}

Kent A. 2008. The effect of changing enclosure design on ring-tailed lemur (lemur catta) behaviour. Dissertation The University of Reading.

Mallapur A. 2005. Managing primates in zoos: Lessons from animal behaviour. Current Science 89, No. 7.

Simpson L. 2004. The effect of visitors on captive non-human primates in: Zoo Federation Research Newsletter 5, No. 3. Sussman R.W. 1977. Feeding Behaviour of Lemur Catta and Lemur Fulvus pgs 1-31. In Primate Ecology: Studies of feeding and ranging behaviour in lemurs, monkeys and apes. Academic Press Inc (London) Ltd.

Williams C. and Litten-Brown J.C. 2008. Proceedings of the British Society of Animal Science, 146. 